$\xi=-1$

\title{
A Conceptual Model on Websites Design Features for Self-Management of Chronic-Diseases Patients
}

\author{
Farhana Aini Saludin ${ }^{1}$, Nurazean Maarop ${ }^{1}$, Norziha Megat Mohd Zainuddin¹, Roslina Mohammad², Sya Azmeela \\ Shariff ${ }^{1}$
}

\author{
${ }^{1}$ Advanced Informatics School (AIS), Universiti Teknologi Malaysia (UTM) \\ ${ }^{2}$ Razak School of Engineering and Advanced Technology, UTM \\ *Corresponding author E-mail: farhanafour@gmail.com
}

\begin{abstract}
Undeniably, there are several reasons to be connected to the Internet. In healthcare, finding health information from the Internet and websites is common among the global community. Searching health information over the Internet can assists chronic-disease patients in self-managing their health condition. Self-management program with Information Technology empowerment would improve time, distance and traffic barriers because it is easily accessible, up-to-date, and offers tailored feedback to patients' health status. There is great demand of health websites use though at the same time users are facing concerns and limitations due to medical jargons use and navigational problems. Hence, there is a strong reason why more studies need to be conducted in this particular area especially in the design and development of health websites. Based on a review of relevant papers, this paper aims to propose a model for websites design features for self-management of chronic-diseases patients. Ten relevant features of health websites are extracted and proposed in this study. The study may be beneficial to health websites users and eventually improve their health conditions.
\end{abstract}

Keywords: Self-management, health websites, web design features, health information

\section{Introduction}

Yearly, non-communicable disease or also known as chronic diseases were the major health burden to the Malaysian society. In 2014, non-communicable diseases are account to $73 \%$ of total death with cardiovascular related diseases were the highest causes. Surviving with chronic-disease requires one to have a strong determination for gaining health improvements [1]. Even though chronic diseases treatment are costly [2], diseases can be prevented and can be effectively controlled through diet, exercise, rational drug use, self-monitoring and education [3], [4]. Thus patients need to be essentially managed over time [5]. According to the standard care, the ability of self-management approaches in providing more benefits to the patients' health status and wellbeing is getting more evidently strong [6]. Self-management program with Information Technology (IT) empowerment would improve these issues in terms of improving time, distance and traffic barriers because it is easily accessible, up-to-date, and tailored feedback to patients` health status [7]. The role of World Wide Web and Internet helps to improve patients' health status [8]. The online effort has improved knowledge gaining and understanding in users which include the change in diets, smoking cessation, moderating alcohol and managing medicine effectively [9]. These indicate a positive impact that health websites in selfmanagement have to once health status. Many web users especially the elderly, less educated and those with various health problems still found difficulties in using the Internet to find for health information [10], [11]. As an example, several problems were faced by a group of rheumatic disease patients in searching for online health information such as difficulties in formulating a search query, evaluating the source of information and scanning for the relevant information [12]. By ensuring website design compliance with the comprehensive guidelines, the websites will work for everyone in terms of providing better service quality and thus increase web quality and user satisfactions. There were many attempts to develop comprehensive and established guidelines for web design. However, study of websites quality have pointed out this requires complex concepts understanding and was not easily identifiable [13]. Lack of web guidelines design in Malaysian context is one of the problems that need to be address. Hence, this study focuses to fill in this gap by proposing web design features model of health related area.

\section{Theoretical Background}

The Chronic-care Model (CCM) design to assists the management of chronic-diseases among patients and healthcare team [14] and thus help to improve patient's health [15]. This model describes the essential elements in health care system which includes community, the health system, self-management support, delivery system design, decision support and clinical information systems. Self-management is one of the key principle in CCM which had been identified as the area that need most improvement [16]. The needs of chronic-disease patients to be managed at all-time require extensive and on-going management. Self-management with IT interventions were said to be ideal and effective [17], [18]. Daily exhaustive self-management activities such as monitoring eating habits, medication taking and monitoring can best be supported through the technology facilitations such as handheld devices and web-based tools [19]. Figure 1.0 shows The CCM and its elements. 


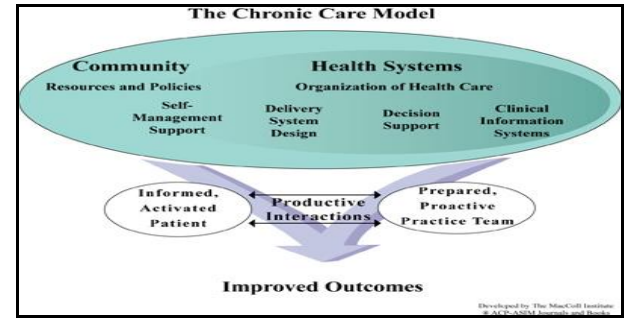

Figure 1.0 The Chronic Care Model [20]

Web-based self-management is found to be effective in improving health outcome [21] and its design requires additional attention compare to normal websites [22]. Website features are typical elements of a websites which are visible to users [23] and can drive visitors to the websites [24]. Appropriate websites features will help in promoting positive experiences to users, improve organizations digital footprint and increase visitors engagements to the websites [25]. Studies on how website features influence web visitors have been conducted broadly. Technology Acceptance Model (TAM) had been used widely to study a person decisions in using a medium or technology and to describe the relationships [21]. Recently, in health education, Hassan, Win, \& Hyland (2013), had conducted a study on design features of Online Patient Education (OPE) websites for chronic diseases and its benefits. Their study indicates that from 29 features for OPE websites found in literature, only 23 features were significant. Patient tailored information and interactivity features resulted to be the most important group of features compared to others (presentations of content, content, interpretability, multimedia graphic). The study also validated perceived benefits of OPE website which is derived from health outcome and social outcome. These benefits may facilitate the process of building a better website [27]. The significant of patient education in chronic diseases management is similar to the self-management of chronic diseases. Both are believed to assists in diseases management and healthcare behaviour. According to the CCM [28], selfmanagement is one of the key principle that was designed to promote and improve health quality. OPE system and selfmanagement websites were both mentioned to be persuasive systems [22], [29].

Identifying design features for a websites is important in fulfilling users' expectation. Design features for self-management websites need to be identified in order to assists users in self-managing their health and thus improve their health and social outcomes. Therefore, this study considers mainly OPE design feature [26] model (Figure 2.0) as well as CCM [27] as the foundation of this study.

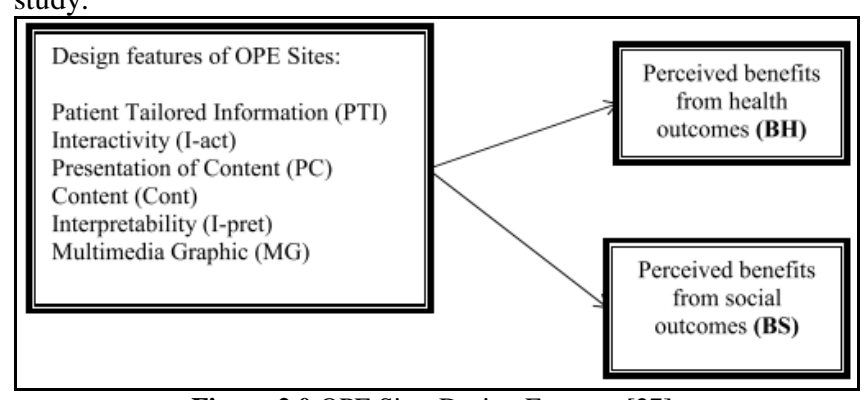

Figure 2.0 OPE Sites Design Features [27]

\section{Research Methodology}

This study has reviewed other researches of web design features in health related context. Literature review was conducted to identify the potential web design features for self-management websites to address the research questions; "What are the web design features for chronic disease patients self-management?". The search strategy comprises four phases, 1) paper identification, 2) screening, 3) eligibility and 4) inclusion. Related articles were identified by searching articles from PubMed, SAGE Journals and Journal of the American Medical Association (JAMA). The searching was conducted between August to September 2016. The databases were chosen due to its relevancy for journals in the field of Medical and Health Informatics. Additionally, Google Scholar and snowballing technique on the reference lists of the included paper were also performed. Search keyword used in this study included combination of 'website features' OR 'health websites' OR 'health websites' features. Articles published from 2004 and up to September 2016 were searched from the selected databases. Potential article record titles and abstract were then screened for further review if the article fulfill the criteria of English article, full-text articles, and comprise of web features related to health. Only articles from empirical research that reported findings related to healthcare domain, self-management elements, IT-relevant features and chronic-disease management were included for analysis and synthesis. Finally, the web features related to health and health websites were extracted based on the findings. Based on review, this study proposes a conceptual model of a website design features that takes into consideration of self-management elements that influence chronic disease patients' health and social outcome. Figure 3.0 shows the research design process of this study.

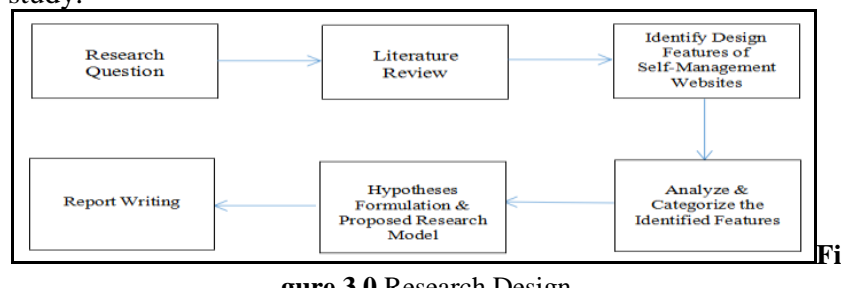

\section{Results \& Discussions}

Website features are the elements that need to be on a website [25] which portray the look and feel of a website, its functionality and content that can attract visitors[24]. This section presents the findings of the review regarding the relevant features that need to be considered in developing health website. Ten features were extracted based on the criterions. On the other hand perceived benefits were selected as the dependent variable in the proposed model of Health Website Features Model.

\subsection{Technical Aspects}

Zhang \& Von Dran (2000) defines technical aspects features of a website are features that related to the basic functions of a website. This includes web browser support and indication of system loading. Tarafdar \& Zhang (2005) stated that technical properties of a website covers security features, speed of download, speed of display content, accessibility and reliability. Presence of SMS alert which is sent to mobile phone when the website is updated may encourage users to log on to the websites. Revisiting to the websites help users to be more involved in their own healthcare [32].

\subsection{Navigation}

Zhang \& Von Dran (2000) indicates that navigation features are features that are related to moving around the website. Some sections of a website can sometime be visited unintentionally by web visitors. This can be caused either by the participants are curious or the sign was confused and not clear [33]. Findability is a measure how easily specific health-related content can be found by information consumer [34]. In order to improve the findability of a website, health websites are proposed to dynamically refresh their home page based on consumers` search and click-through habits [34]. Navigation menu and links on the homepage are rarely 
used. Search box is more popular method. Therefore, providing additional features such as faceted search, metaphor exploration, multi-dimensional views and trending topics to improve websites findability. Familiarity with the usage of Web 2.0 may improve participants in gaining more knowledge, skills, and mastery experience in reinforcing strategies by health websites of selfmanaged patients [35].

\subsection{Audio/Visual Content}

Audio or video content categories refer to features related to sounds and video. Voice narrator is a non-visual techniques that supports the accessibility of the content and content navigation [36]. Voice narrator was found helpful in e-mobile devices health participants, Diabetes and You and Child Care Center [37] Graphics together with text and voice were helpful indicating that listening help in participants reading [37].

\subsection{Interactivity}

Interaction with other participants of the websites provides users ways to communicate likely to traditional face-to-face meetings. Support from peer users are perceived to be related to the higher $\log$-in in to the websites [38]. Online self-management support has been perceived to enable networking and peer interaction among cancer survivors [39].

\subsection{Self-Monitoring}

Self-monitoring features include the capabilities of a participant of the websites to be aware of their food and calories, exercise and changes in weight [40]. Continuous monitoring is important so that patients could be alerted with the immediate effects of the health behavior they take such as food intake, exercises and medication [41]. To know their daily progress is likely seen as encouragement and motivation for them to continue to control their behavior [40]. Meanwhile, using mobile phones for selfmonitoring had been said to be cost-efficient [42]. This is due to the nature of mobile phones that is "always on" and "always worn" and it offers affordable, proximate, personalized and continuous measurement in context [42].

\subsection{Patient-Tailored Information}

Access to up-to-date health information is difficult due to the limited time users have and broad coverage of health information [43]. Improving access to health information does not just involve citations and references, but the information need to be filtered and synthesized. Information overload from the website potentially could distract people from the website and therefore reduce the website usage [44]. Information on the websites should not only be personalized to health background, but also personalization should be made according to user`s location, culture and language [45]. User should be able to see the overview of the website content, and then select more detail information personalized to their individual needs [29], [44]. Personalized websites were evident to increase patients` satisfaction, improve understanding of disease and increase ability to involve in managing diseases [46].

\subsection{Trust}

The issue of trust in health domain is another significant feature According to Sillence et al. (2007), users usually spend more time visiting websites that consists in-depth content with a specific facts and knowledge. Content related features such as Question \& Answer (Q\&A) section, glossary and referencing were more important in terms of trust compare to the design related features such as layout arrangement. Web users may rather trust websites that contain high-quality information [48].

\subsection{User-Friendliness}

User-friendly is one of the criterions to build a successful health system or websites. Websites that is built based on this criterion will save end users time and effort during their first time used [49]. Information that is displayed in variety of ways and can be filtered according to specific category make the information more user-friendly [43]. Multilanguage function, adjustable color contrast and toolbar for screen reader to read text on sites [29], navigation structures, search options and feedback [50] can help to increase websites user-friendliness. A website that is user-friendly can encourage the non-expert user to achieve satisfaction with the content of a website [51].

\subsection{Entertainment}

Entertainment is group of web features that make the website enjoyable, entertaining and fun [30]. Avatars are normally found in virtual reality computer games. Avatar can be design in a computer-generated (CG) animation style or in two-dimensional (2D) cartoon character style [52]. Young people who are engaged in online cancer counseling through avatar have been reported to have positive experiences [53]. Meanwhile, the use of avatars for children with autism has shown the interest that they are willing to interact with avatars and stimulate responses [52]. Additionally, a focus group participants stated that reward system is a requirement for application involving overweight and obesity self-management [40]. Earning rewards based on weight loss or making or sustaining health behaviors was perceived as a way to stay motivated [40]. Rewards can in terms of virtual badges, medals or accessories for avatars [40]. Games elements in a websites or online games have been said to cause Internet addiction disorder [54]. However, games can also promote social interaction, fostering participations and increase engagement with communities [55]. The sharing of interest, identities and mutual support increase participants' engagement in health promotion practices.

\subsection{Gamification}

Game-based approaches have been used to engage patients in treatment. Gamification is one of the game-based approaches where game design elements is apply to the design of a system where the application of game designs elements into the design of a system or an existing activity[56]. Game-based approaches are design to make self-care activities and treatments more enjoyable, motivating and engaging. Rewarding elements of game-based approach helps in motivating users towards healthy behavior especially when that find it difficult to start or maintain [57].

\subsection{Perceived Benefits}

Patient education and self-management concepts deal with health information and the goals is to improve health outcomes and increases the support for patients. Perceived benefits constructs justify that people tend to adopt healthier behaviors when they believe the new behavior will reduce their chances of developing a disease. Perceived benefits of health educational websites comprises of two categories which are health benefits and social benefits[29]. Health benefits include improved health outcomes, health education and knowledge acquisition, patient awareness, patient confidence towards treatment, self-care behavior and selfcare management, reduced hospitalization and adherence to treatment. Meanwhile, social benefits are improved quality of interaction with physician, easy access to educational material, time and cost effectiveness, improved social support, patient 
emotional state and satisfaction. Additionally, self-management websites perceived benefits are to enable networking and peer interaction amongst patients, help survivors (cancer) feel like they are no longer a patient, provide access to resources 24 hour a day, reduced time before follow-up individual issues and reduced readmittance after discharge as problems tacked early, or without the need for admittance [39]. Therefore, each web design features was hypothesized to have the influence on the perceive benefits of its users.

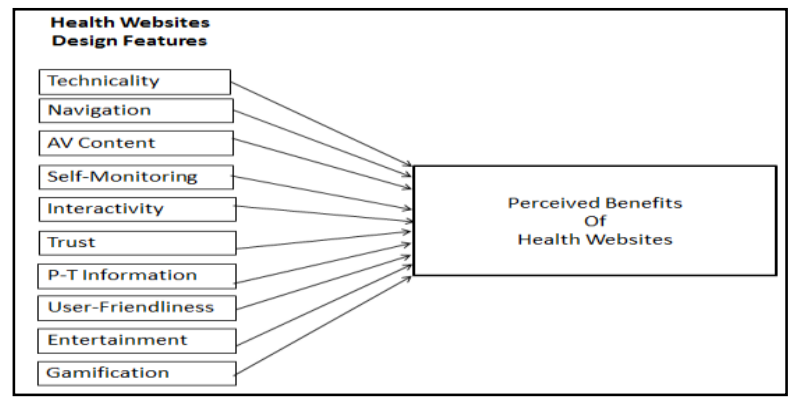

Figure 4.0 Proposed Research Model of Health Website Features

The proposed framework as shown in Figure 4 hypothesizes that each design features of health websites will effects the perceived benefits of self-management health websites. Overall, the study hypothesizes:

H1: Technicality has a significant effect on the perceived benefits of health websites.

H2: Navigation has a significant effect on the perceived benefits of health websites.

H3: Audio Video Content has a significant effect on the perceived benefits of health websites.

H4: Self-Monitoring has a significant effect on the perceived benefits of health websites.

H5: Interactivity has a significant effect on the perceived benefits of health websites.

H6: Trust has a significant effect on the perceived benefits of health websites.

H7: Patient Tailored Information has a significant effect on the perceived benefits of health websites.

H8: User-Friendliness has a significant effect on the perceived benefits of health websites.

H9: Entertainment has a significant effect on the perceived benefits of health websites.

H10: Gamification has a significant effect on the perceived benefits of health websites.

\section{Conclusions}

The understanding of how web design features influence web users especially patients is important for the patients' health improvements and it is crucial and valuable to explore. This study presents relevant features in regard to the design and usage of health websites as a tool for self-management of patients with chronic disease. This design features model for self-management of chronic disease patients helps to recognize the various components of web-based features. As the global society now is depending on the online information especially health related information, more effort should be in place whereby content provider and health organization must put forth a higher commitment in making their websites less vulnerable and more reliable.

\section{Acknowledgements}

We would like to express our greatest appreciation to Ministry of Education and Universiti Teknologi Malaysia for supporting the study. UTM Vote No: Q.K130000.2540.15H36

\section{References}

[1] I. J. C. Heart, H. Li, and J. Ge, "Cardiovascular diseases in China : Current status and future perspectives," IJCHA, vol. 6, pp. 25-31, 2015.

[2] D. O. Abegunde, C. D. Mathers, T. Adam, M. Ortegon, and K. Strong, "The burden and costs of chronic diseases in low-income and middle-income countries," Lancet, vol. 370, no. 9603, pp. 1929-1938, 2007.

[3] World Health Organization, "a vital investment," 2005.

[4] Y. Tu, Y. Huang, and F. Yi, "Chronic Disease Management System Design Based on Cloud Storage Architecture,” pp. 654-658, 2015.

[5] H. Holman and K. Lorig, "Patient self-management: A key to effectiveness and efficiency in care of chronic disease," Public Health Rep., vol. 119, no. 3, pp. 239-243, 2004.

[6] J. Barlow, C. Wright, J. Sheasby, A. Turner, and J. Hainsworth, "Self-management approaches for people with chronic conditions: A review," Patient Educ. Couns., vol. 48, no. 2, pp. 177-187, 2002.

[7] M. Kyung, Y. Ho, H. Park, E. Sook, K. Hae, and D. Noh "International Journal of Nursing Studies A Web-based selfmanagement exercise and diet intervention for breast cancer survivors : Pilot randomized controlled trial §," Int. J. Nurs. Stud., vol. 51, no. 12, pp. 1557-1567, 2014

[8] K. R. Lorig, P. L. Ritter, D. D. Laurent, and K. Plant, "Internetbased chronic disease self-management: a randomized trial.," Med. Care, vol. 44, no. 11, pp. 964-971, 2006.

[9] E. Murray, "Web-based interventions for behavior change and selfmanagement: Potential, pitfalls, and progress," Journal of Medical Internet Research, vol. 14, no. 4. 2012.

[10] P. C. Pang, K. Verspoor, and J. Pearce, "INNOVATION IN DESIGNING HEALTH INFORMATION WEBSITES : RESULTS FROM A QUANTITATIVE STUDY WEBSITES: RESULTS FROM A QUANTITATIVE STUDY," 2016.

[11] M. Benigeri, "Shortcomings of health information on the Internet," Health Promot. Int., vol. 18, no. 4, pp. 381-386, Dec. 2003.

[12] R. Van Der Vaart, C. H. C. Drossaert, M. De Heus, E. Taal, and M. A. F. J. Van De Laar, "Measuring actual ehealth literacy among patients with rheumatic diseases: A qualitative analysis of problems encountered using health 1.0 and health 2.0 applications," J. Med. Internet Res., vol. 15, no. 2, 2013.

[13] L. Mich, M. Franch, and L. Gaio, "Evaluating and designing web site quality," MultiMedia, IEEE, vol. 10, no. 1, pp. 34-43, 2003.

[14] V. J. Barr, S. Robinson, B. Marin-Link, L. Underhill, A. Dotts, D. Ravensdale, and S. Salivaras, "The expanded Chronic Care Model: an integration of concepts and strategies from population health promotion and the Chronic Care Model.," Hosp. Q., vol. 7, no November 2003, pp. 73-82, 2003.

[15] K. Coleman, B. T. Austin, C. Brach, and E. H. Wagner, "Evidence On The Chronic Care Model In The New Millennium,” pp. 75-85, 2009.

[16] USAID Health Care Improvement Project, "Supporting Patient Self-Management to Improve," 2012.

[17] G. Hu, Y., Peng, C., \& Bai, "Sharing Health Data Through Hybrid Cloud for Self-Management," o Work. (ICMEW), 2015 IEEE Int. Conf., pp. 1-6, 2015.

[18] A. L. K. Ms, M. P. H. Rd, R. Wray, and C. M. Lerouge, "Perceptions of Adolescents with Overweight and Obesity for the Development of User-Centered Design Self-Management Tools within the Context of the Chronic Care Model: A\&nbsp;Qualitative Study," J. Acad. Nutr. Diet., pp. 1-11, 2015.

[19] L. M. Siminerio, "The Role of Technology and the Chronic Care Model," vol. 4, no. 2, pp. 470-475, 2010.

[20] P. M. Gee, D. A. Greenwood, D. A. Paterniti, D. Ward, and L. M. S. Miller, "The eHealth enhanced chronic care model: A theory derivation approach," J. Med. Internet Res., vol. 17, no. 4, p. e86, 2015.

[21] H. Eide and S. Van Dulmen, "Patient Education and Counseling Web-based, self-management enhancing interventions with ediaries and personalized feedback for persons with chronic illness : A tale of three studies “" f Birna Kristja," vol. 93, pp. 451-458, 
2013.

[22] H. Mukhtar, A. Ali, D. Belaid, and S. Lee, "Persuasive healthcare self-management in intelligent environments," Proc. - 8th Int. Conf Intell. Environ. IE 2012, pp. 190-197, 2012.

[23] Y.-K. Cheong and R. L. Shehab, "Building a Web-Features Taxonomy for Structuring Web Design Guidelines," Proc. Hum. Factors Ergon. Soc. Аnnu. Meet., vol. 47, no. 11, pp. 1361-1365, 2003.

[24] Willetts, "Website Features List," 2012. [Online]. Available: http://www.willetts.com/content/features.html. [Accessed: 10-Sep2016]

[25] L. Drell, "10 Essential Features of Every Good Business Website," 2012. [Online]. Available: http://mashable.com/2012/02/09/website-musthaves/\#K2F6Ap8dUiqD. [Accessed: 10-Sep-2016].

[26] N. M. Hassan, K. T. Win, and P. Hyland, "Exploring Design Features and Benefits of Online Patient Education (OPE) Sites for Chronic Diseases," 2013 46th Hawaii Int. Conf. Syst. Sci., pp. 2454-2463, Jan. 2013.

[27] N. M. Hassan, "Identifying design features of online patient education for chronic disease management," University of Wollongong, 2013.

[28] E. H. Wagner, "Chronic Disease Management: What Will It Take To Improve,” pp. 2-4, 1998.

[29] K. T. Win, N. M. Hassan, H. Oinas-Kukkonen, and Y. Probst, "Online Patient Education for Chronic Disease Management: Consumer Perspectives," J. Med. Syst., vol. 40, no. 4, pp. 1-13, 2016.

[30] P. Zhang and G. M. Von Dran, "Satisfiers and dissatisfiers: a twofactor model for website design and evaluation," J. Am. Soc. Inf Sci. Technol., vol. 51, no. 14, pp. 1253-1268, 2000.

[31] M. Tarafdar and J. Zhang, "Analysis of critical website characteristics: a cross-category study of successful websites," $J$. Comput. Inf. Syst., vol. 46, no. 2, pp. 14-24, 2005.

[32] K. T. Win, N. M. Hassan, A. Bonney, and D. Iverson, "Benefits of Online Health Education: Perception from Consumers and Health Professionals," J. Med. Syst., vol. 39, no. 3, 2015.

[33] L. S. Franck and G. Noble, "Here's an idea: ask the users! Young people's views on navigation, design and content of a health information website.," J. Child Health Care, vol. 11, no. 4, pp. 287-97, Dec. 2007.

[34] H. W. Samuel, O. R. Za, and J. Robertson, "Findability in Health Information Websites," vol. 25, no. Bhi, pp. 709-712, 2012

[35] M. Stellefson, B. Chaney, A. E. Barry, E. Chavarria, B. Tennant, K Walsh-Childers, P. S. Sriram, and J. Zagora, "Web 2.0 chronic disease self-management for older adults: A systematic review," Journal of Medical Internet Research, vol. 15, no. 2. 2013.

[36] B. Raufi, M. Ferati, X. Zenuni, J. Ajdari, and F. Ismaili, "Methods and Techniques of Adaptive Web Accessibility for the Blind and Visually Impaired," Procedia - Soc. Behav. Sci., vol. 195, pp. 1999-2007, 2015.

[37] P. Wright, "Health Information via the Internet 1 Abstract Prosdex design,” pp. 321-332, 2010.

[38] R. A. Krukowski, J. Harvey-Berino, T. Ashikaga, C. S. Thomas, and N. Micco, "Internet-based weight control: the relationship between web features and weight loss.," Telemed. J. E. Health., vol. 14 , no. 8, pp. 775-82, 2008.

[39] L. Moody, A. Turner, J. Osmond, L. Hooker, J. Kosmala-Anderson, and L. Batehup, "Web-based self-management for young cancer survivors: consideration of user requirements and barriers to implementation," J. Cancer Surviv., vol. 9, no. 2, pp. 188-200, 2015

[40] A. L. Knoblock-hahn, R. Wray, and C. M. Lerouge, "Perceptions of Adolescents with Overweight and Obesity for the Development of User-Centered Design Self-Management Tools within the Context of the Chronic Care Model: A\&nbsp;Qualitative Study," J. Acad. Nutr. Diet., pp. 1-11, Oct. 2015.

[41] M. A. Al-Taee, A. H. Sungoor, S. N. Abood, and N. Y. Philip, "Web-of-Things inspired e-Health platform for integrated diabetes care management," 2013 IEEE Jordan Conf. Appl. Electr. Eng. Comput. Technol., pp. 1-6, 2013.

[42] N. Ramanathan, D. Swendeman, W. S. Comulada, D. Estrin, and M. J. Rotheram-Borus, "Identifying preferences for mobile health applications for self-monitoring and self-management: Focus group findings from HIV-positive persons and young mothers," Int. J. Med. Inform., vol. 82, no. 4, pp. 1-15, 2013.

[43] H. Korjonen, "The Obesity Learning Centre (OLC) - a website supporting those working towards a healthy weight and reducing obesity levels.," Online J. Public Health Inform., vol. 3, no. 1, pp. 1-13, 2011.

[44] C. H. Yu, J. A. Parsons, S. Hall, D. Newton, A. Jovicic, D. Lottridge, B. R. Shah, and S. E. Straus, "User-centered design of a web-based self-management site for individuals with type 2 diabetes - providing a sense of control and community," pp. 1-16, 2014.

[45] J. S. Dhillon, B. Wunsche, and C. Lutteroth, "Designing and evaluating a patient-centred health management system for seniors," J. Telemed. Telecare, vol. 22, no. 2, pp. 96-104, 2016.

[46] M. A. Mcclellan, R. P. Karumur, R. I. Vogel, V. Sue, J. Cragg, D. Chan, J. A. Jacko, F. Sainfort, A. Melissa, M. A. Mcclellan, R. P. Karumur, R. I. Vogel, V. Petzel, J. Cragg, D. Chan, J. A. Jacko, F Sainfort, M. A. Geller, M. A. Mcclellan, R. P. Karumur, R. I. Vogel, S. V Petzel, J. Cragg, D. Chan, J. A. Jacko, F. Sainfort, and M. A. Geller, "Designing an Educational Website to Improve Quality of Supportive Oncology Care for Women with Ovarian Cancer: An Expert Usability Review and Analysis Designing an Educational Website to Improve Quality of Supportive Oncology Care for Women with Ovarian ," vol. 7318, no. March, 2016.

[47] E. Sillence, P. Briggs, P. Harris, and L. Fishwick, "Health Websites that people can trust - the case of hypertension," Interact. Comput., vol. 19, no. 1, pp. 32-42, 2007.

[48] Y. Kim, "Trust in health information websites: A systematic literature review on the antecedents of trust," Health Informatics $J$., 2014.

[49] M. Agarwal and S. Goel, "Expert system and it's requirement engineering process," Int. Conf. Recent Adv. Innov. Eng., pp. 1-4, 2014.

[50] J. Stinson, R. Wilson, N. Gill, J. Yamada, and J. Holt, "A systematic review of internet-based self-management interventions for youth with health conditions.," J. Pediatr. Psychol., vol. 34, no. 5, pp. 495-510, 2009.

[51] Z. Zahidi and P. C. Woods, "Understanding the User Experience ( UX ) Factors that Influence User Satisfaction in Digital Culture Heritage Online Collections for Non-Expert Users," pp. 57-63, 2014.

[52] E. J. Carter, J. Hyde, D. L. Williams, and J. K. Hodgins, "Investigating the Influence of Avatar Facial Characteristics on the Social Behaviors of Children with Autism," Proc. 2016 CHI Conf. Hum. Factors Comput. Syst. - CHI '16, pp. 140-151, 2016.

[53] C. Phelps, M. Minou, A. Baker, C. Hughes, H. French, W. Hawkins, A. Leeuwenberg, R. Crabtree, and P. B. Hutchings, "Necessary but not sufficient? Engaging young people in the development of an avatar-based online intervention designed to provide psychosocial support to young people affected by their own or a family member's cancer diagnosis," Heal. Expect., 2016.

[54] S. S. Alam, N. Mohd, H. Nik, and M. Ahmad, "Negative and positive impact of internet addiction on young adults :," vol. 10, no. 3, pp. 619-638, 2014

[55] K. M. N. Boulos and S. Wheeler, "The emerging Web 2.0 social software: an enabling suite of sociable technologies in health and health care education.," Health Info. Libr. J., vol. 24, no. 1, pp. 2 23, 2007.

[56] F. Nunes, N. Verdezoto, G. Fitzpatrick, M. Kyng, E. Grönvall, and C. Storni, "Self-Care Technologies in HCI: Trends, Tensions, and Opportunities," ACM Trans. Comput. Interact., vol. 22, no. 6, pp. $1-45,2015$.

[57] A. Al Marshedi, G. B. Wills, and A. Ranchhod, "The wheel of sukr: A framework for gamifying diabetes self-management in Saudi Arabia," Procedia Comput. Sci., vol. 63, no. Icth, pp. 475-480, 2015. 